\title{
An SPRi Biosensor for Determination of the Ovarian Cancer Marker HE4 in Human Plasma
}

\author{
Beata Szymanska ${ }^{1}$, Zenon Lukaszewski ${ }^{2}{ }^{(D}$, Beata Zelazowska-Rutkowska ${ }^{3}{ }^{\mathbb{D}}$, \\ Kinga Hermanowicz-Szamatowicz ${ }^{4}$ and Ewa Gorodkiewicz ${ }^{1 \text {,* }}$ \\ 1 Bioanalysis Laboratory, Faculty of Chemistry, University of Bialystok, Ciolkowskiego 1K, \\ 15-245 Bialystok, Poland; b.szymanska@uwb.edu.pl \\ 2 Faculty of Chemical Technology, Poznan University of Technology, pl. Sklodowskiej-Curie 5, \\ 60-965 Poznan, Poland; zenon.lukaszewski@put.poznan.pl \\ 3 Department of Pediatric Laboratory Diagnostics, Medical University of Bialystok, Waszyngtona 17, \\ 15-274 Bialystok, Poland; zelazowskab@wp.pl \\ 4 Comprehensive Cancer Center, Department of Clinical Oncology, Ogrodowa 12, 15-027 Bialystok, Poland; \\ kiniaziel@wp.pl \\ * Correspondence: ewka@uwb.edu.pl
}

\section{check for}

updates

Citation: Szymanska, B.;

Lukaszewski, Z.;

Zelazowska-Rutkowska, B.;

Hermanowicz-Szamatowicz, K.;

Gorodkiewicz, E. An SPRi Biosensor for Determination of the Ovarian Cancer Marker HE4 in Human Plasma. Sensors 2021, 21, 3567. https://doi.org/10.3390/s21103567

Academic Editors: Arnaud Buhot and María Jesús Lobo-Castañón

Received: 31 March 2021

Accepted: 17 May 2021

Published: 20 May 2021

Publisher's Note: MDPI stays neutral with regard to jurisdictional claims in published maps and institutional affiliations.

Copyright: (c) 2021 by the authors. Licensee MDPI, Basel, Switzerland. This article is an open access article distributed under the terms and conditions of the Creative Commons Attribution (CC BY) license (https:/ / creativecommons.org/licenses/by/ $4.0 /)$.

\begin{abstract}
Human epididymis protein 4 (HE4) is an ovarian cancer marker. Various cut-off values of the marker in blood are recommended, depending on the method used for its determination. An alternative biosensor for HE4 determination in blood plasma has been developed. It consists of rabbit polyclonal antibody against HE4, covalently attached to a gold chip via cysteamine linker. The biosensor is used with the non-fluidic array SPRi technique. The linear range of the analytical signal response was found to be $2-120 \mathrm{pM}$, and the biosensor can be used for the determination of the HE4 marker in the plasma of both healthy subjects and ovarian cancer patients after suitable dilution with a PBS buffer. Precision (6-10\%) and recovery (101.8-103.5\%) were found to be acceptable, and the LOD was equal to $2 \mathrm{pM}$. The biosensor was validated by the parallel determination of a series of plasma samples from ovarian cancer patients using the Elecsys HE4 test and the developed biosensor, with a good agreement of the results (a Pearson coefficient of 0.989). An example of the diagnostic application of the developed biosensor is given-the influence of ovarian tumor resection on the level of HE4 in blood serum.
\end{abstract}

Keywords: cancer markers; ovarian cancer; HE4; SPRI biosensors; array of measuring points

\section{Introduction}

Human epididymis protein 4 (HE4), also known as recombinant WAP four disulfide core domain protein 2 (WFDC2), is used as an ovarian cancer marker. HE4 may be used as a marker of ovarian cancer alone or jointly with the other ovarian cancer marker CA 125 as a component of ROMA (risk of ovarian malignancy algorithm) [1,2]. The marker may be present in several isoforms with different molecular weights [1,3]; therefore, its concentration is usually expressed in pM (picomole/L). Serous HE4 concentration is strongly elevated in the case of ovarian cancer, although a certain elevation is also observed in cervical and breast cancers [4], as well as in chronic kidney disease [5]. Moreover, marker concentration strongly depends on the stage of ovarian cancer. The HE4 concentration above which ovarian cancer is diagnosed (cut-off) depends on menopausal status, and surprisingly, the method used for HE4 determination [6,7]. Four analytical methods are currently used for serum HE4 diagnostics: ELISA, chemiluminescence enzyme immunoassay (CLEIA), electrochemiluminescence immunoassay (ECLIA), and chemiluminescent microparticle immunoassay (CMIA) [1]. These methods are implemented using commercially available automated immunoassays provided by Fujirebio Diagnostics (ELISA and CLEIA), Abbott Diagnostics (CMIA), and Roche Diagnostics (ECLIA) with various cut-off values. Despite the different detection techniques, these four immunoassays all have a 
sandwich construction consisting of two antibodies. The first antibody is used for HE4 entrapment from the analyzed sample, while the second is conjugated with a label that creates the analytical signal $[6,7]$. In the case of the most frequently used ECLIA, the second antibody is conjugated with a ruthenium(II) bipyridyl complex, which generates a light impulse triggered by the potential impulse. The alternatively used HE4 ELISA kit [8] also contains a label creating an indirect colorimetric analytical signal. In attempts to develop new methods for HE4 determination, more attention should be paid to label-free analytical techniques such as electric cell-substrate impedance sensing (ECIS), quartz crystal microbalance (QCM), surface acoustic wave (SAW), and SPR. A simple localized surface plasmon resonance (LSPR) biosensor with silver nanoparticles and the anti-HE4 antibody was developed for marker determination in blood serum [8]. This biosensor was updated for analytical signal enhancement [9]. Protein G is covalently immobilized on the silver nanoparticles, and an anti-HE4 antibody is attached to protein G. Such a biosensor is suitable for the determination of the HE4 marker in urea. Recently, a molecularly-imprinted photo-electrochemical sensor was developed for HE4 determination [10], as was a chemiluminescence immunoassay with HE4 accumulation on magnetic particles [11]. The aim of the present paper was to develop a much simpler, label-free immunosensor for HE4 determination based on a single antibody and the SPRi technique.

The non-fluidic array version of the SPRi technique, already used for the determination of the ovarian marker CA 125 [12], exhibits analytical characteristics (LOQ) suitable for the determination of cancer markers in blood. In contrast to fluidic SPR, a biosensor is created ex situ, measurement is performed after the gentle removal of processing liquids [13], and no signal enhancements is needed to attain the required LOQ. An array of $9 \times 12$ measuring points enables the measurement of nine different samples [14] (see Figure 1). The chips are regenerable [15]. In the SPR imaging technique, a surface plasmon resonance signal is converted into an image recorded by a CCD camera. This differs from fluidic SPR, where a sensorgram is recorded, i.e., changes of an SPR signal in time, and from localized SPR, where the analytical signal is a shift in the localized surface plasmon resonance spectrum. Certainly, the physical nature of signal creation is the same in all three techniques: the successive immobilization of a receptor and an analyte causes changes in the refractive index on the chip surface and consequently changes in the SPR signal (a lowering of the SPR dip and a shift of the angle of polarized light). SPRi simply records reflected light using a CCD camera. The non-fluidic array version of the SPRi technique enables the determination of approximately 20 biomarkers without signal enhancement or the preliminary preconcentration of analyte $[16,17]$, which is the advantage of this technique over the fluidic version of SPR.

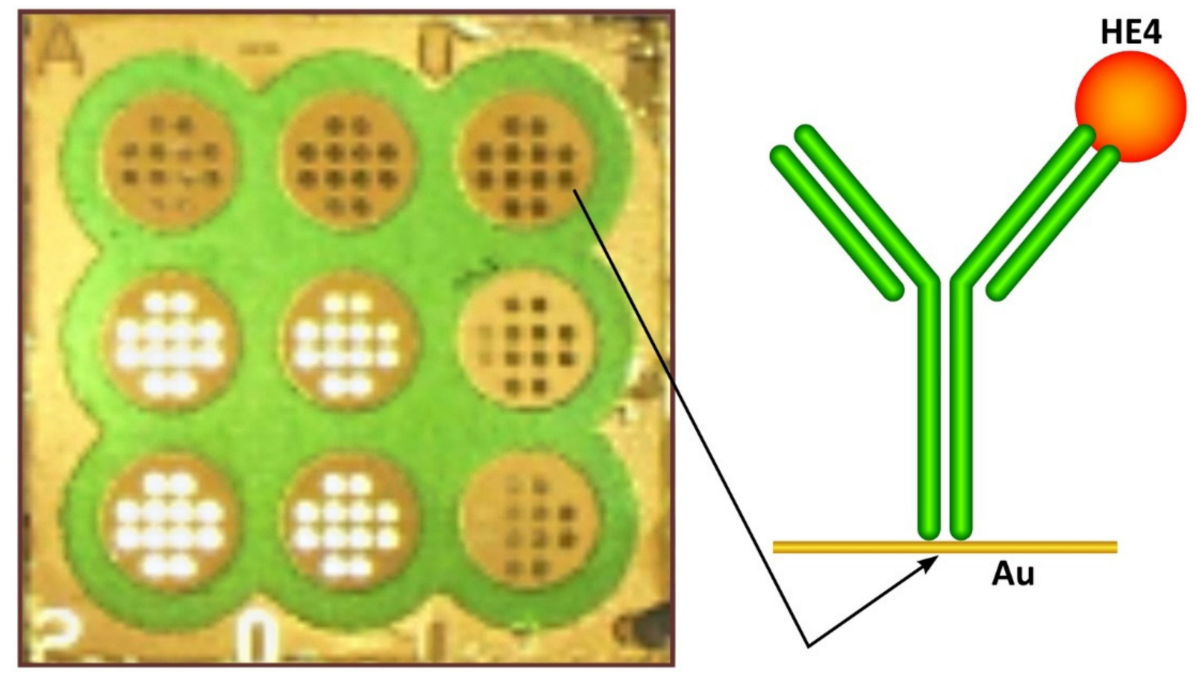

Figure 1. Chip architecture and sketch of biosensor. 
Serous ovarian cancer samples exhibit an HE4 concentration above $150 \mathrm{pM}$, with maximal values above $850 \mathrm{pM}$ [4], while the marker level for healthy premenstrual women ranges between 15 and $62 \mathrm{pM}$ [18]. The cut-off value for HE4 in serum is recommended at between 70 and $87 \mathrm{pM}$ for premenstrual and between 112 and $140 \mathrm{pM}$ for postmenstrual women, depending on the method used for marker determination [6,7]. HE4 exhibits good selectivity and specificity (with an ROC (receiver operating characteristic) curve with an area under the curve (AUC) value of 0.91) and strongly reacts to the disease stage [4]. It should be noted that urine HE4 concentration is much higher than the serous marker concentration, and it is significantly elevated in the case of ovarian cancer [5]. The designed biosensor appears to be suitable for the determination of HE4 in both healthy individuals and ovarian cancer patients. Initial experiments showed that a biosensor consisting of cysteamine as the linker and covalently immobilized rabbit polyclonal antibody against HE4 is a suitable tool for the determination of the marker in blood plasma. Cysteamine (mercaptoethyleneamine) is bonded to the gold surface by a mercapto group, while an amine group enables the attachment of the antibody via the NHS/EDS protocol. The carboxy group of the Fc region of the antibody (opposite the Fab antigen-binding site) is used to form an amide bond with the amine group of cysteamine.

\section{Experimental}

\subsection{Materials and Reagents}

Human epididymis protein 4 (HE4) (MW of $44 \mathrm{kDa}$ ) (Cloud-Clone Corp., Houston, TX, USA), rabbit polyclonal antibody against HE4 (ABCAM plc, Cambridge, MA, USA), cysteamine hydrochloride, N-ethyl- N'-(3-dimethylaminopropyl) carbodiimide (EDC), human albumin (all SIGMA, Steinheim, Germany), and N-hydroxysuccinimide (NHS) (ALDRICH, Munich, Germany) were used. The bases of the biosensors were chips covered with a layer of gold (Sens, Netherlands).

A complete list of materials and reagents is given in Appendix A.1.

\subsection{Biological Material}

The plasma samples used for the tests came from donors from the Regional Blood Donation and Blood Treatment Center in Bialystok, as well as from patients with ovarian cancer and endometrial cyst from the Maria Sklodowska-Curie Oncology Center. All samples were provided after obtaining the consent of the Bioethical Commission.

\subsection{Procedures}

\subsubsection{Antibody Immobilization}

In the first stage of antibody immobilization, the gold chip was covered with cysteamine linker by immersion in a $20 \mathrm{nM}$ ethanolic cysteamine solution for at least $12 \mathrm{~h}$; the chip was subsequently rinsed with absolute ethanol and water, and it was dried under an argon stream. The chip with cysteamine was stable over several months. Antibody immobilization was performed following the EDS/NHS protocol, as described (for example) in [19], with rabbit polyclonal antibody against HE4. For this purpose, the antibody was activated with a mixture of EDC $(250 \mathrm{nM})$ and NHS $(250 \mathrm{nM})$ in a carbonate buffer $(\mathrm{pH} 8.5)$ and applied to the chip previously covered with cysteamine. After incubation for $60 \mathrm{~min}$ at $37^{\circ} \mathrm{C}$, the chip was washed with water. In order to eliminate nonspecific adsorption, after the incubation of the chip with the antibody, a bovine serum albumin (BSA) solution with a concentration of $1 \mathrm{ng} \mathrm{mL} \mathrm{m}^{-1}$ was applied to the biosensor active sites and then washed several times with redistilled water before being dried under a stream of argon.

\subsubsection{SPRi Measurements}

SPRI measurements were performed as previously described $[14,20]$. A home-made apparatus and chip architecture were used, as described in Appendix A.2. The chip architecture and a sketch of the biosensor are shown in Figure 1. The SPRi signal was measured twice, after the immobilization of the antibody and then after interaction with 
a solution containing HE4 at a constant light angle. A $3 \mu \mathrm{L}$ plasma sample or a standard solution of HE4 was placed on an immunosensor for $10 \mathrm{~min}$ and then washed with an HBS-ES buffer and water. The buffer and water were removed from the chip surface by means of a vacuum.

\section{Results and Discussion}

\subsection{Optimization of Antibody Concentration}

The optimization of the concentration of the rabbit polyclonal antibody against HE4 was performed at a constant HE4 concentration (114 pM). A description of these experiments is given in Appendix A.3. On the basis of these experiments, an antibody concentration of $20 \mathrm{ng} \mathrm{mL}^{-1}$ was selected as the optimal value for further experiments.

\subsection{Dependence of the Analytical Signal on HE4 Concentration. Calibration Graph}

The analytical response of the developed biosensor was investigated for a range of HE4 concentrations between 2 and $1140 \mathrm{pM}$. Experiments were performed as described in Sections 2.3.1 and 2.3.2 at an antibody concentration of $20 \mathrm{ng} \mathrm{mL}^{-1}$. The results are plotted in Figure 2. The typical Langmuirian shape of the curve was the result of the gradual saturation of the active points of the biosensor. The initial section of the curve was linear and suitable for analytical purposes. The linear range was from 2 to $110 \mathrm{pM}$. Higher concentrations could be determined after suitable dilution. Compared to the results of Yuan et al. [8], who also used an anti-HE4 antibody as a reception element and reported linearity in the semilogarithmic co-ordinate system from $10 \mathrm{pM}$, this work provided straight linearity from $2 \mathrm{pM}$. On the other hand, the biosensor described in this paper requires the dilution of more concentrated samples, while that of Yuan et al. was found to ensure linearity over three orders of magnitude of HE4 concentration [8].

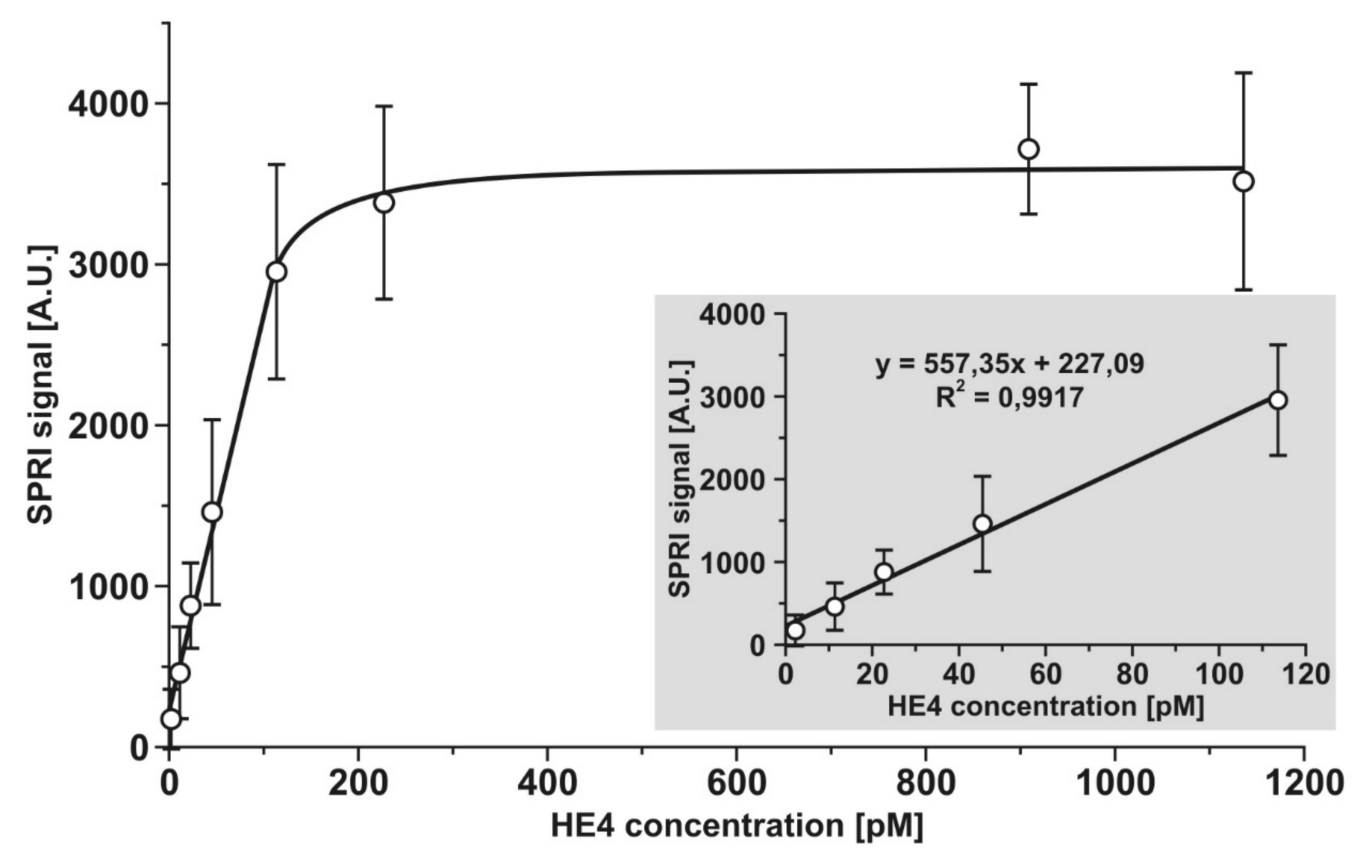

Figure 2. Dependence of the analytical signal on HE4 concentration. Calibration graph.

\subsection{Precision and Recovery. Limit of Detection}

Three series of experiments were performed to investigate the precision and recoveries of the developed biosensor. The selected spikes of HE4 are located at the beginning, middle, and end of the linear section of the calibration graph. Each series consisted of 24 single measurements. The obtained results are shown in Table 1. 
Table 1. Precision and recovery of HE4 with the developed biosensor $(n=24)$.

\begin{tabular}{ccccc}
\hline $\begin{array}{c}\text { Added } \\
(\mathbf{p M})\end{array}$ & $\begin{array}{c}\text { Found } \\
(\mathbf{p M})\end{array}$ & $\begin{array}{c}\text { SD } \\
(\mathbf{p M})\end{array}$ & $\begin{array}{c}\text { RSD } \\
\mathbf{( \% )}\end{array}$ & $\begin{array}{c}\text { Recovery } \\
\mathbf{( \% )}\end{array}$ \\
\hline 11.4 & 11.6 & 0.68 & 6.0 & 101.8 \\
45.5 & 46.5 & 4.5 & 9.9 & 102.1 \\
114 & 118 & 11 & 9.6 & 103.5 \\
\hline
\end{tabular}

The results showed that the precision and recoveries of the measurements of HE4 concentration made using the developed biosensor were acceptable and typical for such a determination. The limit of detection determined on the basis of three SD of blank was $2 \mathrm{pM}$.

\subsection{Specificity of the Developed Biosensor}

The specificity of the analytical response of the developed biosensor is a crucial factor, because in natural samples, the HE4 marker is present in an environment containing a huge number of other biologically active substances. Albumin and markers (cancer antigen 125 (CA 125), carcinoembryonic antigen (CEA), interleukin 6 (IL-6), aromatase, and metalloproteinase 2 (MMP 2)) were selected for these experiments. The highest excess of albumin and the CA 125 marker (1000:1) was applied because albumin is the most common protein in human blood and CA 125 is frequently used jointly with HE4 in ovarian cancer diagnosis. A constant HE4 concentration (114 pm), together with different excesses of potential interferents, was used in all tests. The results are shown in Figure 3.

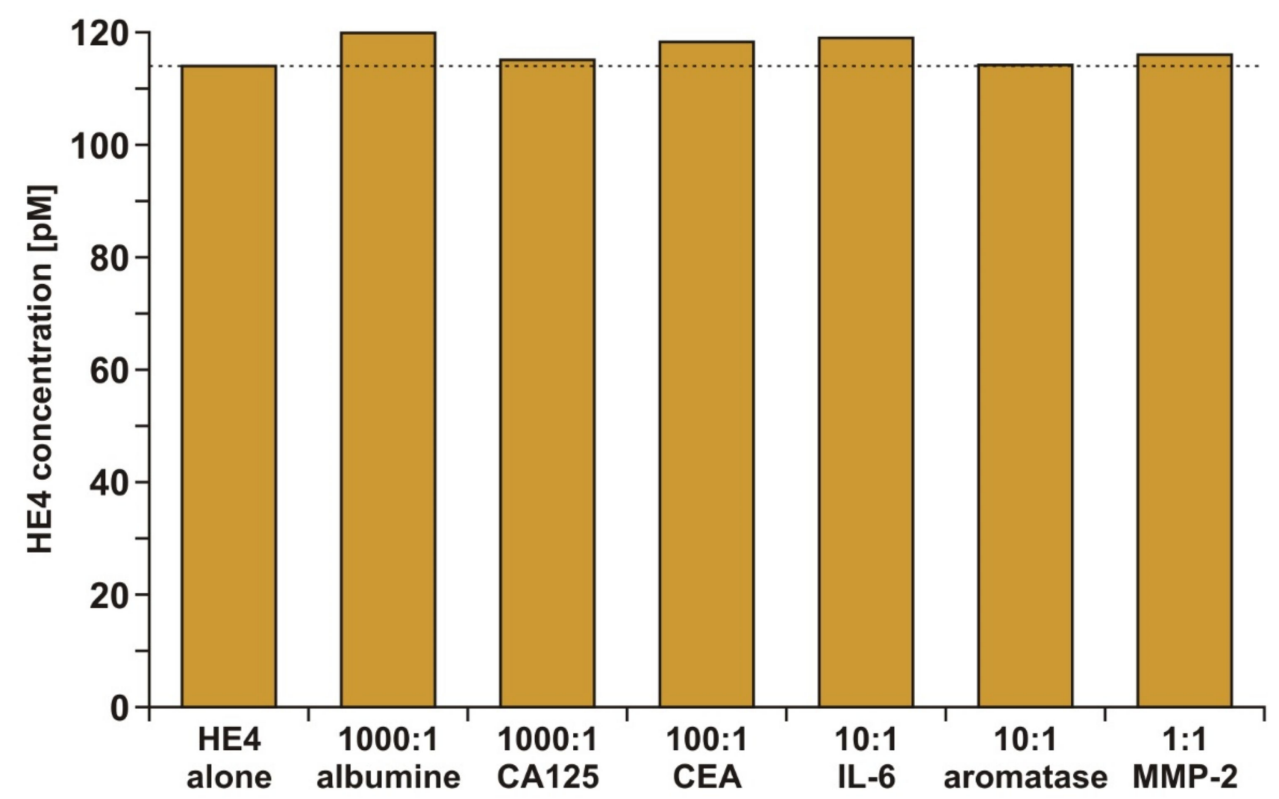

Figure 3. Specificity of HE4 determination. The determination of HE4 (114 pM) in the presence of variable excesses of potential interferents.

The results showed that none of the investigated potential interferents had a significant influence on the HE4 analytical signal.

\subsection{Validation of the Developed Biosensor}

The validation of the developed biosensor was performed by the parallel determination of HE4 by the developed biosensor and a standard method in a series of blood serum samples from patients with ovarian cancer. The standard method was the Elecsys HE4 electrochemiluminescence performed on COBAS E-411. The results showed an acceptable correlation (a Pearson coefficient of 0.989). For a better comparison of the results of both methods, a Bland-Altman plot was made (Figure 4). 


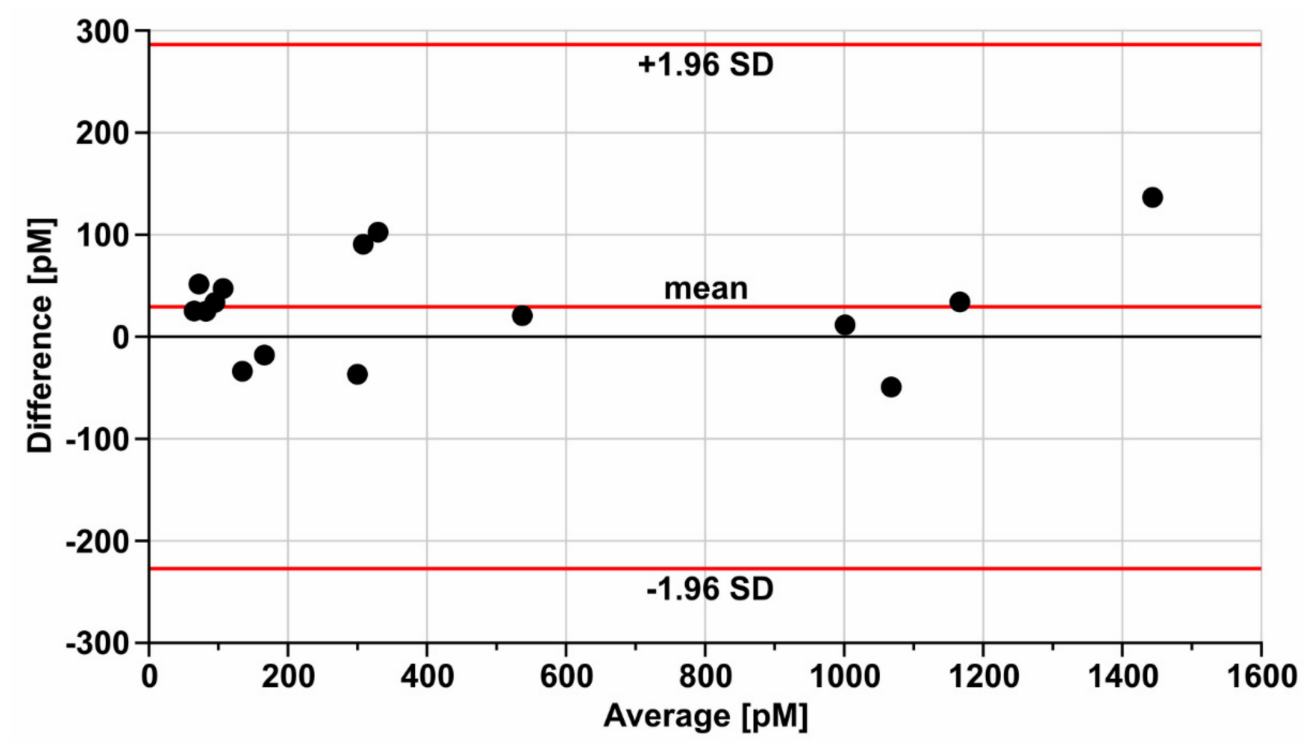

Figure 4. Bland-Altman plot for the HE4 results determined by a standard method (Elecsys HE4 performed on COBAS E-411) and the developed biosensor.

The plot indicated the acceptable agreement of both methods. The results obtained with the developed biosensor exceeded those of the standard method by approximately $20 \mathrm{pM}$. This difference was acceptable when considering that four currently used automatic methods for HE4 determination give different results $[6,7]$. Thus, the validation of the developed biosensor was completed.

\subsection{Example of Diagnostic Application}

To demonstrate the diagnostic effectiveness of the developed biosensor, the HE4 concentration in the blood serum of ovarian cancer patients before and after tumor resection was investigated. Serum from seven patients was tested for $\mathrm{HE} 4$ concentration before resection and after 6 h, 24 h, and 5 days after resection. Average values are shown in Figure 5. The average value of HE4 concentration in blood serum is included for comparison.

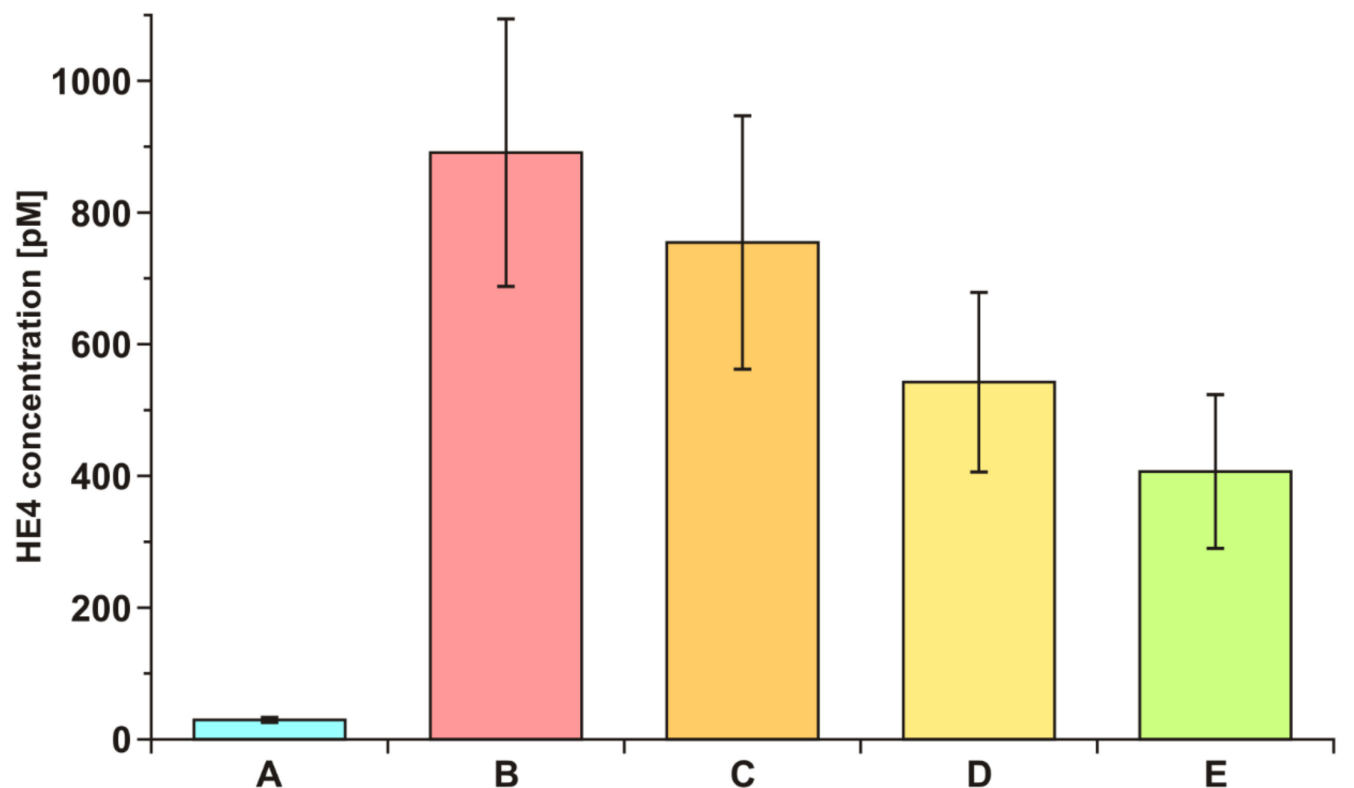

Figure 5. HE4 concentration in blood serum of ovarian cancer patients $(\mathrm{n}=7)$ before $(\mathrm{B})$ and after $6 \mathrm{~h}$ (C), $24 \mathrm{~h}(\mathrm{D})$, and 5 days (E) after tumor resection. (A) healthy volunteers $(\mathrm{n}=18)$. 
A very fast decrease in the HE4 concentration after resection was observed, as was a much higher HE4 level in the serum of ovarian cancer patients than in healthy donors. These experiments confirmed that the developed biosensor may be a useful tool in the diagnosis of the disease.

\section{Conclusions}

A biosensor suitable for HE4 determination in the blood plasma of both healthy subjects and ovarian cancer patients was developed. The biosensor exhibited a linearity of the analytical signal response and acceptable precision and recovery. It was validated by the parallel determination of a series of plasma samples from ovarian cancer patients using the Elecsys HE4 test and the developed biosensor, with an acceptable agreement of the results. The influence of ovarian tumor resection on the level of HE4 in the blood serum, as determined by the developed biosensor, provided examples of its diagnostic application. The developed biosensor can extend the series of previously developed biosensors used with the non-fluidic array version of the SPRi technique, including biosensors for the determination of cathepsins B, D, G, L, and S; laminin-5; fibronectin; collagen IV; proteasome $20 \mathrm{~S}$ and immunoproteasome 20S; UCHL-1; MMP-1 and MMP-2; aromatase; podoplanin; leptin; CA 125; CEA; and cystatin C. Many of these biosensors have been used in clinical investigations. Thus, a new diagnostic tool has been added to this series. Certainly, the simple construction of biosensors in the non-fluidic array version of the SPRi technique has some limitations. To resolve more complex analytical problems such as microRNA [21] and anti-cancer drug bleomycin [22] determination in human serum, an amplification of the SPR signal could be used.

Author Contributions: B.S. data curation, investigation, and formal analysis; Z.L. writing-review and editing; B.Z.-R. Elecsys HE4 measurements performed on COBAS E-411 and validation; K.H.-S. collection of biological samples, formal analysis, and validation; E.G. conceptualization, supervision. All authors have read and agreed to the published version of the manuscript.

Funding: This research was funded by Polish Ministry of Education and Science grant number BST-162.

Institutional Review Board Statement: The study was conducted according to the guidelines of the Declaration of Helsinki, and approved by the Bioethics committee at the Medical University of Bialystok, nr R-I-002/304/2019.

Informed Consent Statement: Informed consent was obtained from all subjects involved in the study.

Data Availability Statement: Not applicable.

Acknowledgments: This article has received financial support from the Polish Ministry of Science and Higher Education under subsidy for maintaining the research potential of the Faculty of Chemistry, University of Bialystok.

Conflicts of Interest: The authors declare that they have no known competing financial interests or personal relationships that could have appeared to influence the work reported in this paper.

\section{Appendix A}

Appendix A.1. Materials

Human epididymis protein 4 (HE 4) (M.W. 44 kDa)(Cloud-Clone Corp., USA), rabbit polyclonal antibody against HE 4 (ABCAM plc, Cambridge, USA), cysteamine hydrochloride, N-Ethyl- N'-(3-dimethylaminopropyl) carbodiimide (EDC), human albumine, (all SIGMA, Steinheim, Germany) and N-Hydroxysuccinimide (NHS) (ALDRICH, Munich, Germany) were used, as well as absolute ethanol (POCh, Gliwice, Poland), HBS- ES solution $\mathrm{pH}=7.4$ (0.01 M HEPES, $0.15 \mathrm{M}$ sodium chloride, $0.005 \%$ Tween 20, $3 \mathrm{mM}$ EDTA), carbonate buffer $\mathrm{pH}=8.50-9.86$, Phosphate Buffered Saline (PBS) $\mathrm{pH}=7.4$, (all BIOMED, Lublin, Poland), HBS- ES solution $\mathrm{pH}=7.4$ (0.01 M HEPES, 0.15 M sodium chloride, 0.005\% Tween 20, 3 mM EDTA), photopolymer ELPEMER SD 2054, hydrophobic protective 
paint SD 2368 UV SG-DG (PETERS, Kempen, Germany) were used as received. Aqueous solutions were prepared with miliQ water (Simplicity ${ }^{\circledR}$ MILLIPORE).

The base of the biosensors were chips covered with a layer of gold (Sens, The Netherlands).

\section{Appendix A.2. Apparatus and Chip Architecture}

SPRI measurements were performed on a home-made apparatus consisting of a $\mathrm{HeNe}$ laser (JDS Uniphase, Edmund Industrial Optics, San Jose, CA, USA), two glass lenses L1 (f $3 \mathrm{~mm}$ ) and L2 (f $300 \mathrm{~mm}$ ), two polarizers (P1 and P2), a mirror, a prism and a CCD camera (QICam, QImaging, Vancouver, BC, Canada). NIH Image J version 1.42 software was used for evaluation of the SPRI images in 2D form.

The chip is an array of 108 active places. It has nine round measuring sites, each with 12 free gold surfaces. Using this chip, nine different solutions can be measured simultaneously without mixing the tested samples, and 12 separate SPRI measurements can be performed from a single $0.3 \mu \mathrm{L}$ droplet of tested solution.

\section{Appendix A.3. Optimization of Concentration of Rabbit Polyclonal Antibody against HE 4}

Optimization of the concentration of rabbit polyclonal antibody against HE 4 was performed at constant HE 4 concentration $(114 \mathrm{pM})$. A chip preliminarily covered with cysteamine was treated with different concentrations of rabbit polyclonal antibody against HE 4 which has been previously activated with a mixture of EDC $(250 \mathrm{nM})$ and NHS $(250 \mathrm{nM})$ in carbonate buffer ( $\mathrm{pH}$ 8.5). After $60 \mathrm{~min}$ of interaction the antibody was covalently immobilized on the chip, which was then rinsed with water and dried under a stream of argon. The first SPRi measurement was performed. The biosensor was treated with $114 \mathrm{pM}$ solution of HE 4, rinsed with HBS-ES buffer and water, and finally dried under the stream of argon, after which the second SPRi measurement was performed. The analytical signal, which is the difference of the first and the second measurements, was plotted as a function of antibody concentration (Figure A1). On the basis of this graph, an antibody concentration of $20 \mathrm{ng} \mathrm{mL}^{-1}$ was selected as the optimal value for further experiments.

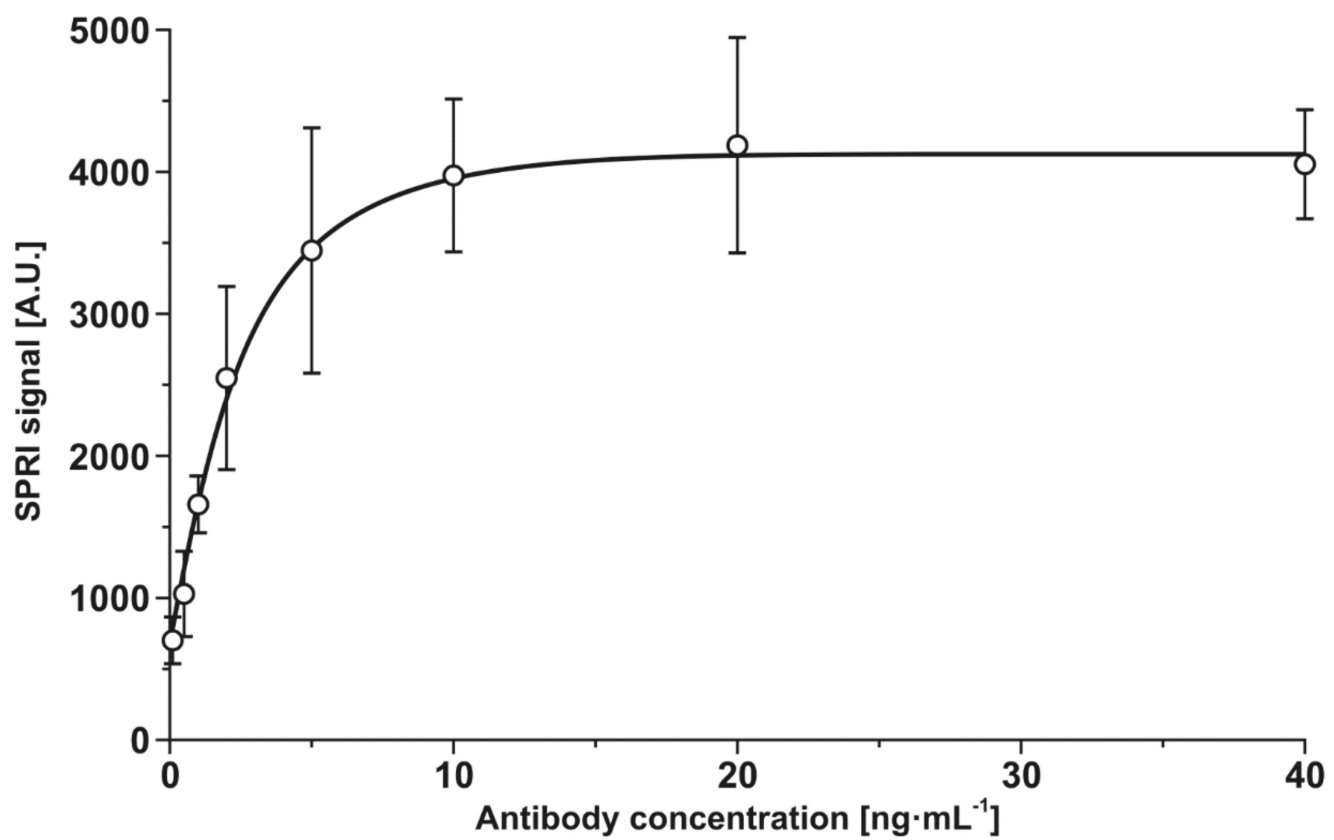

Figure A1. Dependence of the analytical signal on the concentration of rabbit polyclonal antibody against HE 4 , at an HE 4 concentration of $114 \mathrm{pM}$. 


\section{References}

1. Granato, T.; Porpora, M.G.; Longo, F.; Angeloni, A.; Manganaro, L.; Anastasi, E. HE4 in the differential diagnosis of ovarian masses. Clin. Chim. Acta 2015, 446, 147-155. [CrossRef] [PubMed]

2. Kappelmayer, J.; Antal-Szalmás, P.; Nagy, B., Jr. Human epididymis protein 4 (HE4) in laboratory medicine and an algorithm in renal disorders. Clin. Chim. Acta 2015, 438, 35-42. [CrossRef] [PubMed]

3. Bingle, L.; Singleton, V.; Bingle, C.D. The putative ovarian tumour marker gene HE4 (WFDC2), is expressed in normal tissues and undergoes complex alternative splicing to yield multiple protein isoforms. Oncogene 2002, 21, 2768-2773. [CrossRef] [PubMed]

4. Anastasi, E.; Marchei, G.G.; Viggiani, V.; Gennarini, G.; Frati, L.; Reale, M.G. HE4: A new potential early biomarker for the recurrence of ovarian cancer. Tumor Biol. 2010, 31, 113-119. [CrossRef]

5. Fan, Q.; Luo, G.; Yi, T.; Wang, Q.; Wang, D.; Zhang, G.; Jiang, X.; Guo, X. Diagnostic value of urinary-to-serum Human Epididymis Protein 4 ratio in ovarian cancer. Biomed. Rep. 2017, 7, 67-72. [CrossRef]

6. Ferraro, S.; Borille, S.; Carnevale, A.; Frusciante, E.; Bassani, N.; Panteghini, M. Verification of the harmonization of human epididymis protein 4 assays. Clin. Chem. Lab. Med. 2016, 54, 1635-1643. [CrossRef]

7. Ferraro, S.; Panteghini, M. Making new biomarkers a reality: The case of serum human epididymis protein 4. Clin. Chem. Lab. Med. (CCLM) 2018, 57, 1284-1294. [CrossRef]

8. Yuan, J.; Duan, R.; Yang, H.; Luo, X.; Xi, M. Detection of serum human epididymis secretory protein 4 in patients with ovarian cancer using a label-free biosensor based on localized surface plasmon resonance. Int. J. Nanomed. 2012, 7, 2921-2928. [CrossRef]

9. Duan, R.; Xi, M. A Novel Label-Free Biosensor for Detection of HE4 in Urine Based on Localized Surface Plasmon Resonance and Protein G Directional Fixed. J. Nanomater. 2020, 8613240. [CrossRef]

10. Wang, C.; Ye, X.; Wang, Z.; Wu, T.; Wang, Y.; Li, C. Molecularly Imprinted Photo-electrochemical Sensor for Human Epididymis Protein 4 Based on Polymerized Ionic Liquid Hydrogel and Gold Nanoparticle/ZnCdHgSe Quantum Dots Composite Film. Anal. Chem. 2017, 89, 12391-12398. [CrossRef]

11. Fu, X.; Liu, Y.; Qiu, R.; Foda, M.F.; Zhang, Y.; Wang, T.; Li, J. The fabrication of magnetic particle-based chemiluminescence immunoassay for human epididymis protein-4 detection in ovarian cancer. Biochem. Biophys. Rep. 2018, 13, 73-77. [CrossRef]

12. Szymanska, B.; Lukaszewski, Z.; Hermanowicz-Szamotowicz, K.; Gorodkiewicz, E. A biosensor for determination of the circulating biomarker CA125/MUC16 by Surface Plasmon Resonance Imaging. Talanta 2020, 206, 120187. [CrossRef]

13. Gorodkiewicz, E. The Surface Plasmon Resonance Imaging Sensor for Papain Based on Immobilized Cystatin. Protein Pept. Lett. 2007, 14, 443-445. [CrossRef]

14. Tokarzewicz, A.; Romanowicz, L.; Sveklo, I.; Gorodkiewicz, E. The development of a matrix metalloproteinase-1 biosensor based on the surface plasmon resonance imaging technique. Anal. Methods 2016, 8, 6428-6435. [CrossRef]

15. Sankiewicz, A.; Tokarzewicz, A.; Gorodkiewicz, E. Regeneration of surface plasmone resonance chips for multiple use. Bulgar. Chem. Commun. 2015, 47, 477-482.

16. Gorodkiewicz, E.; Lukaszewski, Z. Recent Progress in Surface Plasmon Resonance Biosensors (2016 to Mid-2018). Biosensors 2018, 4, 132. [CrossRef]

17. Falkowski, P.; Lukaszewski, Z.; Gorodkiewicz, E. Potential of Surface Plasmon Resonance Biosensors in cancer detection. J. Pharm. Biomed. Anal. 2021, 194, 113802. [CrossRef]

18. Gasiorowska, E.; Kluz, T.; Lipski, D.; Warchoł, W.; Tykarski, A.; Nowak-Markwitz, E. Human Epididymis Protein 4 (HE4) Reference Limits in Polish Population of Healthy Women, Pregnant Women, and Women with Benign Ovarian Tumors. Dis. Markers 2019, 3890906. [CrossRef]

19. Sankiewicz, A.; Romanowicz, L.; Laudanski, P.; Zelazowska-Rutkowska, B.; Puzan, B.; Cylwik, B.; Gorodkiewicz, E. SPR imaging biosensor for determination of laminin-5 as a potential cancer marker in biological material. Anal. Bioanal. Chem. 2016, 408, 5269-5276. [CrossRef]

20. Sankiewicz, A.; Lukaszewski, Z.; Trojanowska, K.; Gorodkiewicz, E. Determination of collagen type IV by Surface Plasmon Resonance Imaging using a specific biosensor. Anal. Biochem. 2016, 515, 40-46. [CrossRef]

21. Wang, X.; Hou, T.; Lin, H.; Lv, W.; Li, H.; Li, F. In situ template generation of silver nanoparticles as amplification tags for ultrasensitive surface plasmon biosensing of microRNA. Biosens. Bioelectron. 2019, 137, 82-87. [CrossRef] [PubMed]

22. Li, H.; Chang, J.; Hou, T.; Li, F. HRP mimicking DNAzyme-catalyzed in situ generation of polyaniline to assist signal amplification for ultrasensitive Surface Plasmon Resonance biosensing. Anal. Chem. 2017, 89, 673-680. [CrossRef] [PubMed] 